\title{
The Efficacy of Arabic Version of the Developmental Assessment of Young Children Second Edition (DAYC-2) Scale in Detecting Developmental Delay among Jordanian Children Aged Birth to 71 Months
}

\author{
Rawan M. Abu Saleh ${ }^{1} \&$ Jamil M. Smadi ${ }^{1}$ \\ ${ }^{1}$ Special education and Counselling Department, Jordan University, Amman, Jordan \\ Correspondence: Rawan M. Abu Saleh, Special education and Counselling Department, Jordan University, \\ Amman, Jordan. Tel: 962-796-666-166. E-mail: abusalehrawan80@yahoo.com
}

Received: October 21, 2016

Accepted: November 25, 2016

Online Published: March 30, 2017

doi:10.5539/ies.v10n4p113

URL: https://doi.org/10.5539/ies.v10n4p113

\begin{abstract}
This study aimed to assess the efficacy of the developmental assessment of young children second edition (DAYC-2) Scale in detecting Developmental Delay among Jordanian children aged birth to 71 months. Firstly, the scale was translated and reviewed for language and cultural appropriateness. Secondly, the Arabic Jordanian version of the scale was administrated to children diagnosed as developmental delay aged from birth to 48 months in the neurodevelopmental pediatric clinic in Jordan university hospital, and on children aged 48 to 71 months who were diagnosed as developmental delay in special education centers in Capital Amman. The scale was administrated also to normal development children aged 0 to 71 months who visited the Institute for family health-Noor al Hussein foundation and attended preschools in Capital Amman. Total of 310 children aged (0-71months) were enrolled. Construct validity and discriminative validity were verified. Reliability was established through computing Kuder-Richardson Formula 20 (KR-20), test-retest, split half test methods.t-test showed that the scale discriminates between normally developed and developmentally delayed children. One-way ANOVA showed that age has significant effect on the performance of children favoring older age groups using Scheffé multiple comparisons test.Item efficacy was determined by calculating point-biserial correlation coefficients for all items in each domain. The results showed that the scale had good psychometric properties and was capable of detecting developmental delay in children aged from birth to 71 months in Jordan.
\end{abstract}

Keywords: developmental assessment, developmental assessment tool, developmental delay, developmental domains

\section{Introduction}

Developmental Delay is considered to be a universal issue that societies face and negatively influences children's lives as it has major influences on their academic performance and behavioral outcomes. Therefore, the early developmental delay identification seems beneficial as early intervention will lead to optimal developmental outcomes (Guralnick, 2008, p. 95). Scientifically based research confirms that environment has major influence on children's emotional, physical status, it also impacts their cognitive skills which make compensation of any defect later in life very hard. In addition, early experiences are important in developing children's cognitive and language abilities and enhancing their social competence. Delays in language development, social skills, physical and emotional skills are considered as an indicators of specific developmental disabilities later such as communication disorders, intellectual disabilities and autism spectrum disorders (ASDs), cerebral palsy, visual and hearing impairments (Guralnick, 2008; Shonkoff \& Phillips, 2000; Sices, 2007).

Regarding discerning developmentally delayed young children, primary care physicians have a key role in the systems of early detection and early intervention.(Sices,2007).Despite the importance of their role, formal developmental assessment aren't carried out in the pediatric and primary care clinics as they face many barriers that hinder them from performing these procedures such as time limitation and absence of developmental screening measures. All these barriers leave pediatricians to rely on their informal clinical observations and impressions (Voigt, Llorente, Jenson, \& Fraley, 2007). 
Pediatrician impression has good specificity but poor sensitivity and has difficulty recognizing the less obvious delays. When pediatricians use only clinical impressions rather than formal screening tools, evaluation of children's development tend to be less accurate. Pediatricians typically over rely on psychometrically unreliable milestone checklists with unclear referral criteria. Consequently, clinician's unsystematic surveillance misses the vast majority of children with impairing developmental-behavioral problems (Marks, Glascoe, \& Macias, 2011; Sices, 2007, p. 9).

Therefore, the American Academy of Pediatrics adopted a policy in 2001 which states that all infants and young children should be screened for developmental delays at regular intervals using valid reliable standardized developmental screening tools (American Academy of Pediatrics [AAP], 2001).

Early identification of susceptible developmental delay is crucial for many reasons. Most important scientifically well recognized reasons are the importance of early life experiences and the pivotal role of early relationship as well as developmental plasticity which refers to the capacity of the brain to reorganize its structure or function generally in response to change in environment. Early intervention benefits are significantly related to its timing due to the enormous adaptability of the brain in the first three years of life. Therefore, early intervention is more effective than later intervention (Shonkoff \& Phillips, 2000).

Unfortunately, early developmental delays are often not detected in a timely way. Many children are not identified until kindergarten entry or later-well beyond the period in which early intervention is most effective. As a result, opportunities to intervene early to improve children's developmental outcomes are frequently missed (Sices, 2007).

In regard to Arab countries, the issue of early screening is very complicated as there are no reliable and representative estimates of children with disabilities. The differences in disabilities definitions, lack of validated reliable diagnostic measurement tools and focusing on estimating severe obvious disabilities and neglecting less obvious disabilities, and poor access to diagnostic services contribute to varied prevalence estimates of early childhood disabilities. The most important procedures which may help Arab countries in facing these barriers are promoting parents' awareness of developmental milestones, enhancing health care centers in early detection process and providing developmental assessment tools with trusted psychometric properties to detect developmental delays in young children (Khatib, 2015).

Due to Lack of diagnostic tools at the national level for different disabilities in the Hashemite kingdom of Jordan, The Higher Council for the Affairs of Disabled Persons has emphasized in its National Strategy for Persons with Disabilities for years (2007-2015) on the necessity of developing valid, reliable and standardized scales to assess psychological, medical, educational, and social domains, in its efforts to promote reaching children with disabilities and linking them to early intervention programs (The Higher Council for the Affairs of Disabled Persons, 2007).

\subsection{Literature Review}

Global developmental delay (GDD) refers to infants and preschoolers, ages 0-5 years, who present persistent delays of six months or more, in two or more of the following developmental domains: gross/fine motor, speech/language, cognitive, social/personal, and daily living activities whereas specific developmental delay (SDD) represent delay in a single developmental domain but it is more often global, covering two developmental domains or more (Levy, Ornoy, \& Nevo, 2011, p. 57).

There is a confirmed agreement upon recent studies on the central influences of the genetic and environmental factors on child development process. Brain researches expanded our knowledge about how the brain may respond to intervention in first three years of life, they also indicated that traits whether they were inherited or affected by environment are responsive to intervention which would give promises of better developmental outcomes. Early intervention, especially when it is properly adjusted to a child's individual characteristics would decrease the gap between normally developed children and developmentally delayed. These gaps are apt to broaden as the child grew older in absence of early intervention (Shonkoff \& Phillips, 2000).These findings highlight that early detection of developmental delay is an extremely crucial issue as children in this critical period of their lives develop solid basis for cognitive, communicative, physical skills and social- emotional well-being.

Research findings indicate that assessing children's capabilities in early childhood improves our understanding of individual children's developmental progress and status in order to facilitate their development and functional abilities within their environment and improve children's cognitively, emotionally and physically outcomes. Accordingly, Meisels and Atkins-Burnett (1999) define developmental assessment as an ongoing process of 
systematic observation and analysis in order to comprehend the child's capabilities, resources and the caregiving and learning environments that would help him reach the ultimate level of his developmental potential (Meisels \& Atkins-Burnett, 1999, p. 25).

The traditional model for assessing children particularly in the infancy and toddler period is the medical model which is designed to screen children for medical risks. These screening assessments are usually conducted in primary care settings to ensure delivery of appropriate services to all children with an identified problem or risk. Assessing emotional and behavioral domains comes in the second place although pediatrics recognizes their major impact on child's wellbeing and relationships with others. There is a growing change in pediatricians practices in the past decade as they are more interested in assessing cognitive, emotional and language development in children. The pivotal aim of this process is to recognize developmental defects and detect any suspected developmental delays in infants and toddlers (Snow \& Hemel, 2008).

In preschool children, developmental assessment serves the purpose of enhancing learning experiences of young children and assessing skills that are fundamental for school success. It represents a broad systematic process in which cognitive, behavioral, physical and communication domains are assessed in children aged three to six years to establish a comprehensive view of children's strengths and needs and to plan for instruction at school entry. Most assessment procedures focuses on identifying children at risk of developmental delays at transition from home to preschool or reassessing children diagnosed as developmentally delayed at transition from early intervention programs to preschool (Boehm \& Brassard, 2005).

It is essential to pinpoint that assessing one area of development in isolation of other areas would influence our understanding of children's capabilities and challenges since the development of each area is depends on other areas and all developmental functions mature and develop in an integrated way. It is not unusual that disabilities or dysfunctions in one area profoundly affect the emergence of adaptive abilities in other areas (Meisels \& Atkins-Burnett, 1999).

Developmental Domains consist of physical, communication, cognitive, social-emotional and adaptive behavior. This categorization provides an initial mapping of what might be considered an important aspect of children's development to capture early childhood specialist, caregivers, and physicians attention Physical development domain involves gross motor and fine motor skills. Development in motor skills is a prerequisite for cognitive and social development as child's exploring of his environment provides the base for adaptation and learning.

Concerning communication skills, assessing this developmental domain has always been an interest of researchers of early childhood. Its importance has been derived from its strong relation to cognitive and social skills development and also from its ability to predict academic outcomes in the future such as the ability of child's language repertoire at school entry to predict reading skills later on (Snow \& Hemel, 2000; Bagnato, 2007).

Cognitive developmental domain represents a complex system of evolving problem solving behaviors which enables the child to understand complex interrelationships among people, objects, concepts, and events. It also includes understanding, recalling, comparing, and sorting information (Bagnato, 2007). Assessing Cognitive skills is different from assessing other domains as they are not assessed by direct observation as they are assessed through evaluating responses and behaviors that indicate development of skills and concepts.

Social-emotional developmental domain entails an inextricable interrelated dimensions including attachment, behavioral style, personal identity, self-regulation, and social and object play (Bagnato, 2007). Assessing this developmental area is crucial as studies confirm that its development during the first five years offers a view of the psychological growth of the young child (Shonkoff \& Phillips, 2000).

Adaptive behavior can be identified as the ability to use cognitive skills in daily life, and it relies on intellectual capabilities, motor skills and emotional regulation. Adaptive behavior includes the ability to express our needs, build relationships with others, possess motor and self-help skills, and learn functional academic skills. All these skills determine child's ability to function independently (Milne, McDonald, \& Comino, 2012).

In consideration to all above, the major influences of the cognitive, communication, social-emotional, physical and adaptive behavior domains on achieving developmental demands are obvious. Appearance of any developmental issues related to these areas may hinder the normal development of children which stresses the importance of early detection of developmental delays. The earlier identification creates the opportunity to attain early intervention goals but it is also challenging and there are many opportunities of accessing at risk children are missed.

Although developmental testing of young children, whether for screening or evaluation, has limited ability to 
predict future functioning but is a valid and reliable way to assess skills in a variety of domains. The early identification of children who either are experiencing or at risk of developmental delay is based upon the belief that reliable discriminations can be made between typically developing children, and those with developmental issues (Meiseles \& Atkins-burnett, 1999). Standardized screening tools are frequently used to assess child's performance compared to standardized normal children performance. This comparison may be beneficial as it will help in setting realistic goals for the child and identify his needs (Snow \& Hemel, 1999).

In addition to using assessment information to establish a descriptive picture of children's strengths and needs and to plan learning experiences at program entry, regular assessment of children's learning is needed. The usefulness of any developmental measure in monitoring progress in child's performance will not be achieved unless the tool can provide information about the natural behavior of young children in their natural environments through teacher's and parent's observations. This characteristic of developmental assessment tool perfectly matches one of the fundamental elements of early childhood assessment which emphasizes on the necessity of identifying child's strength and weakness within his own developmental ecology (Bagnato, 2005; Neisworth \& Bagnato, 2004).

The instrument used for assessing development should also have trusted psychometric properties, they must undergo extensive testing for validity, reliability, and accuracy and standardized using children and families who represent the cultural, linguistic, and economic diversity of the intended population to be as accurate as possible (AAP, 2001).

In Arab countries, many Arabic versions of internationally known assessment tools were developed and standardized such as: Jordanian version of cognitive skill test (Labdy, 1995), Arabic Version of Stanford Binet Scale (Kilany, 1981), Saudi version of Vineland adaptive behavior Scale (Otaiby, 2005), Jordanian version of Cain-Levine social competency scale (Jamous, 1983). Revising these scales, one may conclude the following: Most of these scales have outdated norms and according to the American Psychological Association, test norms should be reviewed every 10 years (Abu Hammour, Mattar, \& Al-Hmooz, 2015). Secondly, none of these tests and many other adopted tests in Arab countries have assessed the five developmental domains. Thirdly, all these tests were developed for children older than two years.

The Buros Mental Measurement Institute has developed a list of scales and instruments which have good psychometric properties, including adequate sensitivity, specificity, validity, and reliability, and have been standardized on diverse populations which can be implemented by professionals who work with children. The Developmental Assessment of Young Children (DAYC) Scale received two reviews in the Buros Mental Measurement Yearbook as one of the norm referenced scales to assess children aged from birth to 71 months (The Buros Mental Measurement Institute, 2007). The scale has been discussed in numerous books and articles devoted to current assessment practices (Olegtree, 2001; Watson, 2001; Aiken \& Groth-Marnat, 2006; Voress \& Madoxx, 2013).

The Developmental Assessment of Young Children (DAYC) was originally published in 1998.it was developed as an assessment tool to be used to identify developmental delays in the areas specified in the Individuals with disabilities Education Act Amendments of 1997 (IDEA, 1997; Voress \& Madoxx, 2013).

The Developmental Assessment of Young Children-Second Edition (DAYC-2) was published in 2013 in order to improve the original scale. Swartzmiller (2014) indicates in his revision of the scale that the content of the second edition is similar to the first edition, some items have been eliminated or rewarded for clarity. Average item discrimination and item difficulty results were presented for the norm sample.

DAYC-2 is recognized as an individually administered, norm-referenced measure of abilities of young children from birth through age 5 years 11 months in five developmental areas: cognition, communication, social-emotional, physical, and adaptive behavior. It is designed to be completed in the child's natural settings with people and materials familiar to the child.(Voress\&Madoxx,2013) The scores for the items can based on a combination of three sources: Observation of the child in the natural environment; Structured interview with parents and, with permission, other caregivers; and Direct assessment.

In recognition of the significant importance of early identification of developmental delays, several studies have focused on the role of physicians in detecting developmental delay.

A cross-section observational study conducted by Thomas and colleagues (Thomas, Cotton, \& Pan Ratliff-Schaub, 2012) compared between the systematic use of developmental surveillance (assessing child's development by administrating standard set of informal surveillance developmental questions for parents at the time of their child's 9-, 18-, or 24-month health supervision visit) with standardized scored screening methods 
for the detection of early child developmental delay. Results showed that (67\%) of children were identified by screening were not identified by surveillance The study revealed that even with surveillance carried out in a systematic fashion, clinical judgment is ultimately used to determine a diagnosis of developmental delay. In contrast, using validated standardized tool provided the physicians a clear view of children's abilities and helped them in their referral decisions.

Earls, Andrews and Hay (Earls, Andrews, \& Hay, 2009) descriptive study examined various criteria that may influence the pediatrics decision for referral of developmentally delayed children. The results indicated that there was greater likelihood of referral for gross-motor concerns, and this is followed by language/communication concerns. Pediatrics seemed most certain to refer if multiple domains have at-risk scores. They were much less certain about at-risk scores for fine-motor, problem-solving, and social-emotional domains.

Research by Chung, Liu, Chang, Chen, Tang, and Wong (2011) explored the relationship between parental concerns and final diagnosis in children with developmental delay. Their study included 27 child aged less than 7 years was referred for initial evaluation of a suspected developmental delay due to their parent's concerns. The study concluded that parental concerns about language and motor development were the most powerful predictors of developmental delays among children. In contrast, parental concerns about cognitive problems, global delay, and behavioral problems were less likely to identify children with cognitive problems, global delays, and behavioral problems, compared with those with language or motor problems (Chung et al., 2011).

The various domains of development, such as communication, language, gross motor, fine motor, cognitive and adaptive behaviors, are complex and interrelated (Boyle, Decoufle, \& Yeargin-Allsopp, 1994). It is estimated that $15 \%$ to $18 \%$ of all children have developmental or behavioral disabilities in one or more domains (Sices et al., 2004). Due to these facts, the necessity of assessing the five developmental domains has been verified in a number of studies.

Research by Yao-Chia et al. (2011) investigated the developmental impairment in several domains that might be associated with developmental language delay through reviewing records of 56 preschool children with developmental language delay and 31 normally developed children. The results showed that children with language delay were more likely than those in the normally developed children group to have cognitive developmental delay (Mental Development Index $<70)(\mathrm{P}<.001)$ and gross and fine motor delay (gross: 28 [50\%] versus $5[16 \%], \mathrm{P}=.002$; fine: 34 [62\%] versus 11 [35\%]). Children with language delay were significantly more likely to have impairment than normally developed children in gross motor, fine motor, comprehension-conceptual and personal-social domains $(\mathrm{P}=.01, \mathrm{P}=.02, \mathrm{P}=.01, \mathrm{P}=.02$, respectively). This study indicated that preschool children with language delay might suffer delays in other developmental areas. (Yao-Chia et al., 2011)

Many studies focused on the role of standardized developmental tools in detecting developmental delay. Concerning the Developmental Assessment of Young Children (DAYC), second edition scale its proved to be highly valid and reliable, and easy to administer and score. This accessibility was verified in a number of studies conducted to validate this scale.

A non-experimental correlational study conducted by Tripp (Tripp, 2014) attempted to determine if the Developmental Assessment of Young Children (DAYC) scale is useful in predicting future special education eligibility as defined by the State of Tennessee Department of Education, upon subsequent re-evaluation. A total of 74 children were initially evaluated for special education eligibility using the Developmental Assessment of Young Children (DAYC) at age three and re-evaluated three years later using methods and instruments designated by the State of Tennessee Department of Education (Tripp, 2014, pp. 44-45). Use of the positive predictive value indicated that $80 \%$ of these children predicted to be eligible were found to be eligible three years later. The negative predictive value revealed that $57 \%$ of the children predicted to be not eligible were found to be not eligible three years later. Of the five DAYC subtests used as predictor variables, the cognitive measure proved to be most highly correlated with future special education eligibility. The results of this research indicated that the DAYC is reasonably accurate in predicting which 3-year-old children evaluated in preschool will remain eligible three years later. The findings of this study indicated that the DAYC is a useful instrument in predicting future special education eligibility (Tripp, 2014, p. 58).

In Anderson (2006) study(Anderson 2006), the usefulness of the Communication Development subtest of the Developmental Assessment of Young Children (DAYC-CD) as a teacher administered language-screening instrument was examined. Teachers administered the test to 24 children attending Head Start by observing the children in the classroom. The results revealed that the DAYC-CD achieved high levels of diagnostic accuracy for the children whose existing classification of typical language development or language impairment was 
considered accurate by the classroom teachers and it was suitable to be implemented based on classroom observation without disrupting the child's daily routine in the classroom. Therefore, it shows promise as a teacher-administered language-screening instrument (Anderson, 2006).

By reviewing these studies, we can deduce the crucial role of physicians in surveillance systems (Thomas et al., 2012; Earls et al., 2009) and the importance of parental concerns about their children's development (Chung et al., 2011). On the other hand, these studies results also indicated that physicians reliant solely on their clinical impressions and parents' concerns concentration on developmental areas more than others will leave many developmental delays cases undetected. If the development assessment process couldn't comprehensively assess all developmental areas, this would seriously affect the integrity and trustworthy of the process as the developmental areas integrate and affect each other which agrees with Yao-Chia et al. (2011) study. Accordingly, using standardized developmental measurement tools is considered to be the most trustful approach to detect all development delay cases especially if it was able to assess all developmental domains and benefit from caregivers and teacher's observations and concerns (Anderson, 2006).

To the best of our knowledge, there has been only one study in the Jordanian environment which was interested in assessing developmental domains in children. Khatib and Batsh (2008) developed an early detection model for developmental delay in language, cognitive, social-emotional domains for children aged 3-8 years in Jordan. This study didn't include the adaptive behavior and physical developmental domains and included the ages from birth to 3 years. In our aims to fulfill this gap of knowledge, we aimed to adopt a screening measure which would assess the five developmental areas and would include assessing wider age range (Khatib \& Batsh, 2008).

Tripp (2015) study revealed the unique features of the Developmental Assessment of Young Children scale that rationalize choosing it as a development assessment tool. One of these features is the age range covered (from birth to 71 months)which represent the targeted ages in screening and early intervention programs. Another advantage of using DAYC-2 is that it can be administrated through Observation of the child in the natural environment and it assesses child's performance in cognitive, communicative, social-emotional, physical and adaptive behavior domains. On one hand, the Developmental Assessment of Young Children-second edition scale is considered to be a standardized assessment tool as it has trusted psychometric properties and can differentiate normal and delayed development patterns in young children (Buros, 2014). On the other hand, the scale also has authentic assessment advantages as it can be implemented in natural contexts which frees it from conventional testing procedures restrictions and enables it to be used to monitor children's progress in early intervention settings.

\subsection{Research Problems and Its Questions}

Continuous assessment of young children's abilities in their early years is considered to be a priority as these years represent sensitive period in their lives due to the dynamic and complicated nature of children's development from one side and the dual effect of genes and environment from the other side.

Due to the fact that developmental delay will affect child's academic performance and will hinder his social and emotional competencies in the future, identifying developmental issues in the right time will increase the potentiality of overcoming and treating this delay. Therefore, it is apparent that there is a need to provide a valid and reliable culturally and linguistically sensitive developmental measure to assess developmental delays in children from birth to 71 months.

In Jordan, the problem of detecting developmental delays among children is a serious issue. Therefore, there is a need to provide a scale in Arabic to assess the developmental delays in young children younger than six years old.

Since the Developmental Assessment of Young Children Second Edition (DAYC-2) Scale has been used effectively to differentiate between normally developed and developmentally delayed children and it has trustable psychometric properties, it is of importance to translate this scale into Arabic and validate its psychometric properties for the Jordanian context (Voress \& Maddox, 2013). Therefore, the Purpose of this study was to assess the efficacy of the Developmental Assessment of Young Children Second Edition (DAYC-2) Scale (Arabic version) in detecting Developmental Delay among Jordanian children aged birth to 71 months. More specifically, the current study aimed to answer the following questions:

1) What are the validity indices of the Developmental Assessment of Young Children Second Edition (DAYC-2) Scale (Arabic version) of the in the Jordan context?

2) What are the reliability indices of the Developmental Assessment of Young Children Second Edition (DAYC-2) Scale (Arabic version) in the Jordan context? 
3) What is the items efficacy of the Developmental Assessment of Young Children Second Edition (DAYC-2) Scale (Arabic version)?

\subsection{Research Objectives}

The study aimed to develop a Jordanian adaptation of the developmental assessment of young children second edition (DAYC-2) Scale with good psychometric characteristics in terms of validity and reliability.

This study aimed to:

- Develop an Arabian Jordanian adaptation of the developmental assessment of young children second edition (DAYC-2) Scale

- Computing the validity indices Developmental Assessment of Young Children Second Edition (DAYC-2) for age groups (0-71) months

- Computing the reliability indices Developmental Assessment of Young Children Second Edition (DAYC-2) for age groups (0-71) months.

- Recognize the items efficacy of the Developmental Assessment of Young Children Second Edition (DAYC-2) Scale for age groups (0-71) months

\subsection{Significance of the Study}

The Developmental Assessment of Young Children-Second Edition (DAYC-2) scale is considered to be one of the most popular used scales in the United States of America. However, the scale was only administrated to American children

And it is not clear if it would be applicable in Jordanian environment. Therefore, the researchers aimed to provide an Arabic version of the scale which is culturally and linguistically sensitive to the Jordanian environment that would be suitable to be used by pediatrician and primary care providers to identify developmental delay in young children. It may be used also by special education teachers in Jordan to identify developmentally delayed children and monitor their progress in early intervention settings. Another aspect that adds to the contribution of the study is that the five domains of development for age groups (0-71 months) are being assessed in Jordan for the first time.

\subsection{Research Operational Definition of Terms}

Developmental Delay:

Children aged from birth to 5 years who display corresponding significant delay in two or more of the following developmental domains: gross/fine motor, receptive/expressive language, cognition, and socioemotional development and daily living skills. Developmentally delayed children tend to reach developmental milestones in a manner that is generally similar to that of non- delayed children, but at a much slower rate. Developmental delay is identified when there is $40 \%$ delay in specific developmental domain or $25 \%$ delay in two or more developmental domains, or two standard deviation or more below average in two or more developmental domains on standardized tests (Guralnick \& Bricker, 1987).

In this study, developmental delay is defined by calculation General Development Index (Mean=100, Standard deviation=15) which represents total child's scores in Cognitive Communication, Social-Emotional, Physical Development, Adaptive Behavior which consist the Developmental Assessment of Young Children Second Edition (DAYC-2) for age groups (0-6)years.

Developmental Scale:

Standardized measuring tool where items are organized according to developmental series of milestones, Child's performance is compared with performance of a specific group of children according to norms developed through computing ages average of $50 \%$ from the standardized sample on the raw score and mean (Wortham, 2012).

Developmental Scale is defined operationally by the Developmental Assessment of Young Children, Second Edition (DAYC-2) (Arabic version).

\section{Method}

This study employed the observational analytical methodology whereby the scale was administered to the two groups (developmentally normal and developmentally delayed), and the data collected were duly analysed using SPSS v. 20, as follows: 


\subsection{Participants}

Children aged from birth to 48 months diagnosed as developmental delay in the neurodevelopmental pediatric clinic in Jordan university hospital and children aged 48 to 71 months who were diagnosed as developmental delay in special education centers in Capital Amman. The scale also included children from birth to 71 months with normal development who visited the Institute for family health - Noor al Hussein foundation and attended two preschools in Capital Amman. Table 1 shows the distribution of the sample according to age and gender.

Table1. Distribution of the sample

\begin{tabular}{lccccc}
\hline \multirow{2}{*}{ Variable } & \multirow{2}{*}{ Levels } & \multicolumn{2}{c}{ Normal development } & \multicolumn{2}{c}{ Developmentally delayed } \\
\cline { 2 - 6 } & & $\mathrm{n}$ & $\%$ & $\mathrm{n}$ & $\%$ \\
\hline \multirow{2}{*}{ Gender } & Male & 108 & 51.4 & 67 & 67.0 \\
\cline { 2 - 6 } & Female & 102 & 48.6 & 33 & 33.0 \\
\hline \multirow{4}{*}{ Age(months) } & 12 & 57 & 27.1 & 16 & 16.0 \\
\cline { 2 - 6 } & 24 & 32 & 15.2 & 10 & 10.0 \\
\cline { 2 - 6 } & 36 & 33 & 15.7 & 11 & 11.0 \\
\cline { 2 - 6 } & 48 & 24 & 11.4 & 20 & 20.0 \\
\cline { 2 - 6 } & 60 & 34 & 16.2 & 19 & 19.0 \\
\cline { 2 - 6 } & 71 & 30 & 14.3 & 24 & 24.0 \\
\hline
\end{tabular}

\subsection{Instrument}

Our study is based on-The Developmental Assessment of Young Children Second Edition (DAYC-2) scale developed by Voress and Maddox (2013) to assess development in children of ages less than 1 month to 71 months. The scale is consisted of:

- Cognitive Domain: This domain measures conceptual skills: memory, purposive planning decision making, and discrimination.(88 item)

- Communication Domain: This domain measures receptive and expressive language development skills. (78 item)

- Social-Emotional Domain: This domain assess social awareness, social relationships and social competence. (63 item)

- $\quad$ Physical Development Domain: This domain measures gross motor and fine motor skills. (87 item)

- $\quad$ Adaptive behavior Domain: This domain measures independent and self-help functioning (64 item) (Voress \& Maddox, 2013, p. 1). The Growth Development Index (GDI) represents the normative score for the composite of all five domains. The Properties of this scale are:

Validity: Construct validity was demonstrated by examining performance related to age, performance differences among groups, and relationships among domains. Correlations among the domains demonstrated measurement of similar, yet unique abilities.

Reliability: Internal consistency Correlation coefficients for the domains ranged from .89 to $.98 ; 1$ of the 60 coefficients was less than .90 . GDI Correlation coefficients ranged from .98 to .99 . Test-retest domain reliability coefficients ranged from .70 to .91; subdomain coefficients range was .82 to 0.99 (Swartzmiller, 2014).

Maddox (Voress \& Maddox, 2013) was translated into Arabic then administered on a sample of children of ages less than 1 month to 71 months as in Table (1) with the purpose of establishing its psychometric properties.

\subsection{Procedure}

After The Research proposal has been ethically approved by The Academic Research Council in the Deanship of Academic Research at Jordan University, the researchers started administrating the Developmental Assessment of Young Children Second Edition (DAYC-2)-Arabic version to the children in the sample. The scoring was based on structured interviews with parents and teachers and/or direct assessment of the children. The items are scored either" passed" or "not passed", passed items earn 1 point; not passed items were scored 0.

Each domain of the test was completed in 10-20 minutes, depending on the child's age, most of the information needed to complete the scale for infants was obtained by structured interviews with parents therefore the length of time required for completing the test was relatively short. For older children, additional direct assessment was 
needed. Testing on the whole sample was conducted in the period from 10/3/2016 to 20/9/2016.

\section{Results}

First question: What are the validity indices of the Developmental Assessment of Young Children Second Edition (DAYC-2) Scale (Arabic version) in the Jordan context?

To answer this question, validity indices were verified as follows:

\subsection{Content Validity}

After translating the scale into Arabic language it was then presented to eight arbitrators from special education and educational sciences faculty members to verify the scale validity. The rating scale was modified to fit their comments and suggestions as to language and expressions. Comments of the jury bordered only on linguistic and grammatical mistakes. Slight modifications of some items were made and the number of items remaining was 380 as the originally designed scale.

\subsection{Construct Validity}

The hypothetical construct validity of the scale was established by computing intercorrelations among the domains, and discriminant validity. These results were as follows:

\subsubsection{Intercorrelations among the Domains}

To investigate correlations between domains and total score and correlations among the five domains. Correlation coefficients have been calculated using Pearson Correlation Coefficient. The results are presented in Table 2.

Table 2. Correlation matrix among the five domains of the developmental assessment of young children, second edition (Arabic version) scale $(\mathrm{n}=310)$

\begin{tabular}{|c|c|c|c|c|c|c|}
\hline The Domain & Cognitive & Adaptive Behavior & Social-Emotional & Communication & Physical & Total \\
\hline Cognitive & 1 & & & & & \\
\hline Adaptive Behavior & $.940^{* *}$ & 1 & & & & \\
\hline Social-Emotional & $.942^{* *}$ & $.925^{* *}$ & 1 & & & \\
\hline Communication & $.957^{* *}$ & $.939^{* *}$ & $0.948^{* *}$ & 1 & & \\
\hline Physical & $.902^{* *}$ & $.908^{* *}$ & $.872^{* *}$ & $.893^{* *}$ & 1 & \\
\hline Total & $.979^{* *}$ & $.971^{* *}$ & $.966^{* *}$ & $.978^{* *}$ & $.948^{* *}$ & 1 \\
\hline
\end{tabular}

**Correlation is significant at the 0.01 level (2-tailed).

Table2 shows that correlation coefficients among domains of the Developmental Assessment of Young Children (DAYC-2) scale (Arabic version) are significant and they ranged from 0.872 to 0.957 .The highest correlation coefficient was between the cognitive and communication domains (0.957), and the lowest correlation coefficient was between the social-emotional and physical domains (0.872).These correlation coefficients indicate correlation validity between domains. There are significant correlation coefficients between the domains and the total score which represents the sum of the five domains score. The highest correlation coefficient is between cognitive domain and total score $(0.979)$ and the lowest is between physical domain and total score (0.948)

\subsubsection{Discriminant Validity}

To examine the DAYC-2 scale's ability to discern which children actually are delayed from the normally developed children, the scale was administrated on 210 child identified as normal, and 100 child who were clinically diagnosed as developmentally delayed. The t-test for independent samples was then applied, yielding the results presented in Table 2 .

Table 3. The t-test for two independent samples to compute the discriminative validity of the scale

\begin{tabular}{lccccccc}
\hline Domains & Child Status & $\mathrm{N}$ & Mean & Standard deviation & $\mathrm{T}$ & Degrees $\mathrm{f}$ freedom & Statistical significance \\
\hline \multirow{2}{*}{ Cognitive } & Normal & 210 & 40.60 & 22.679 & \multirow{2}{*}{6.118} & \multirow{2}{*}{308} & $.000^{*}$ \\
\cline { 2 - 7 } & Delay & 100 & 25.66 & 13.104 & & & $.000^{*}$ \\
\hline Social-Emotional & Normal & 210 & 35.55 & 18.470 & 7.020 & 308 & \\
\hline
\end{tabular}




\begin{tabular}{|c|c|c|c|c|c|c|c|}
\hline & Delay & 100 & 21.40 & 11.682 & & & \\
\hline \multirow{2}{*}{$\begin{array}{l}\text { Adaptive } \\
\text { Behavior }\end{array}$} & Normal & 210 & 32.98 & 17.295 & \multirow{2}{*}{5.338} & \multirow{2}{*}{308} & \multirow{2}{*}{$.000^{*}$} \\
\hline & Delay & 100 & 22.89 & 10.998 & & & \\
\hline \multirow{2}{*}{ Communication } & Normal & 210 & 42.42 & 21.602 & \multirow{2}{*}{7.645} & \multirow{2}{*}{308} & \multirow{2}{*}{$.000 *$} \\
\hline & Delay & 100 & 24.66 & 12.360 & & & \\
\hline \multirow{2}{*}{ Physical } & Normal & 210 & 53.84 & 23.122 & \multirow{2}{*}{3.857} & \multirow{2}{*}{308} & \multirow{2}{*}{$.000^{*}$} \\
\hline & Delay & 100 & 43.57 & 19.150 & & & \\
\hline Total & & & 205.40 & 101.242 & 6.131 & 308 & $.000^{*}$ \\
\hline
\end{tabular}

*statistically significant at $\alpha=0.01$.

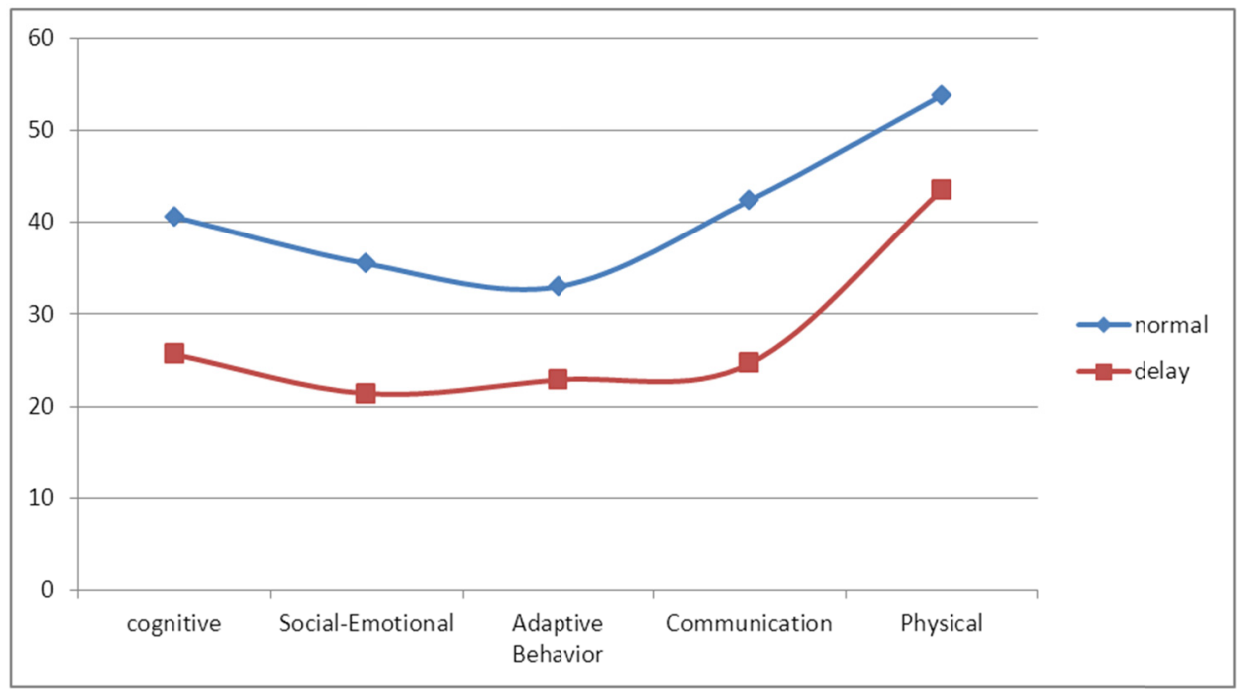

Figure1. Means of scores of normally and developmentally delayed children performance on the five domains

It is apparent from reviewing the table that there is statistically significance differences between normally and delayed developed children performance on each of the scale's five domains and on the total score. All the differences were in favour of normally developed children as it is clear from the mean scores. These differences are also apparent in Figure 1. Therefore, the current results reflect the ability of the scale to correctly identify children who were diagnosed as developmentally delayed and the ability to correctly identify children who were identified as normally developed.

\subsubsection{Discriminant Validity According to Age}

To examine the DAYC-2 (Arabic version) scale's ability to discern between children's performance according to age, one-way ANOVA tests were carried out and the results are shown in Table 4.

Table 4. One-way ANOVA of scores of children on DAYC-2(Arabic version) according to age

\begin{tabular}{|c|c|c|c|c|c|c|}
\hline Domains & Source of variation & Sum of Squares & Degrees of freedom & Mean squares & $\mathrm{F}$ & Sig. \\
\hline \multirow{3}{*}{ Cognitive } & Between groups & 82853.985 & 5 & 16570.797 & \multirow{3}{*}{88.738} & \multirow{3}{*}{$.000 *$} \\
\hline & Within groups & 56768.534 & 304 & 186.739 & & \\
\hline & Total & 139622.519 & 309 & & & \\
\hline \multirow{3}{*}{ Social-Emotional } & Between groups & 52730.179 & 5 & 10546.036 & \multirow{3}{*}{70.236} & \multirow{3}{*}{$.000^{*}$} \\
\hline & Within groups & 45645.770 & 304 & 150.151 & & \\
\hline & Total & 98375.948 & 309 & & & \\
\hline \multirow{3}{*}{$\begin{array}{l}\text { Adaptive } \\
\text { Behavior }\end{array}$} & Between groups & 49660.862 & 5 & 9932.172 & \multirow{3}{*}{95.191} & \multirow{3}{*}{$.000^{*}$} \\
\hline & Within groups & 31719.280 & 304 & 104.340 & & \\
\hline & Total & 81380.142 & 309 & & & \\
\hline Communication & Between groups & 70601.495 & 5 & 14120.299 & 67.674 & $.000^{*}$ \\
\hline
\end{tabular}




\begin{tabular}{lcccccc}
\hline & Within groups & 63430.393 & 304 & 208.653 & & \\
\cline { 2 - 5 } & Total & 134031.887 & 309 & & & \\
\hline \multirow{3}{*}{ Physical } & Between groups & 110476.778 & 5 & 22095.356 & & \\
& Within groups & 44712.461 & 304 & 147.080 & 150.226 & $.000^{*}$ \\
\cline { 2 - 5 } & Total & 155189.239 & 309 & & & \\
\hline Total & Between groups & 1769979.475 & 5 & 353995.895 & 103.063 & $.000^{*}$ \\
\hline & Within groups & 1044165.544 & 304 & 3434.755 & & \\
\hline & Total & 2814145.019 & 309 & & & \\
\hline
\end{tabular}

*Statistically significant at $\alpha=0.01$.

Table 4 clearly shows significant differences between means of all domains due to age. To determine in favor of which groups were the higher performance values, Scheffé's multiple comparison test was performed. Table 5 shows these comparisons.

Table 5. Scheffé's multiple comparisons for discriminative validity according to age for each domain and for the total scale score.

\begin{tabular}{|c|c|c|c|c|c|c|}
\hline Domains & Age & 24 & 36 & 48 & 60 & 72 \\
\hline \multirow{5}{*}{ Cognitive } & 12 & $-15.77560-*$ & $-21.12733-*$ & $-28.05915-*$ & $-41.29672-*$ & $-43.73592-*$ \\
\hline & 24 & & -5.35173 & $-12.28355-*$ & $-25.52111-^{*}$ & $-27.96032-*$ \\
\hline & 36 & & & -6.93182 & $-20.16938-*$ & $-22.60859-*$ \\
\hline & 48 & & & & $-13.23756-*$ & $-15.67677-*$ \\
\hline & 60 & & & & & -2.43920 \\
\hline \multirow{5}{*}{ Social-Emotional } & 12 & $-11.90737-*$ & $-19.20174-*$ & $-23.83811-*$ & $-33.89300-*$ & $-33.60578-*$ \\
\hline & 24 & & -7.29437 & $-11.93074-*$ & $-21.98562-*$ & $-21.69841-*$ \\
\hline & 36 & & & -4.63636 & $-14.69125^{*}$ & $-14.40404-*$ \\
\hline & 48 & & & & $-10.05489-*$ & -9.76768-* \\
\hline & 60 & & & & & .28721 \\
\hline \multirow{5}{*}{ Adaptive Behavior } & 12 & -11.00359-* & $-19.09558-*$ & $-23.23194-*$ & $-31.78211-*$ & $-33.39777-*$ \\
\hline & 24 & & $-8.09199-*$ & $-12.22835-*$ & $-20.77853-*$ & $-22.39418-*$ \\
\hline & 36 & & & -4.13636 & $-12.68654-*$ & $-14.30219-*$ \\
\hline & 48 & & & & $-8.55017-*$ & $-10.16582-*$ \\
\hline & 60 & & & & & $8.55017 *$ \\
\hline \multirow{5}{*}{ Communication } & 12 & $-13.20548-*$ & $-25.86457-*$ & $-29.09184-*$ & $-37.82812-*$ & $-39.27955-*$ \\
\hline & 24 & & $-12.65909-*$ & $-15.88636-*$ & $-24.62264-*$ & $-26.07407-*$ \\
\hline & 36 & & & -3.22727 & $-11.96355-*$ & $-13.41498-*$ \\
\hline & 48 & & & & -8.73628 & $-10.18771-*$ \\
\hline & 60 & & & & & -1.45143 \\
\hline \multirow{5}{*}{ Physical } & 12 & $-26.75114-*$ & $-37.00872-*$ & $-39.98599-*$ & $-48.44611-*$ & $-49.43633-*$ \\
\hline & 24 & & $-10.25758-*$ & $-13.23485-*$ & $-21.69497-*$ & $-22.68519-*$ \\
\hline & 36 & & & -2.97727 & $-11.43739-*$ & $-12.42761-*$ \\
\hline & 48 & & & & $-8.46012-*$ & $-9.45034-*$ \\
\hline & 60 & & & & & -.99022 \\
\hline \multirow{5}{*}{ Total } & 12 & $-78.64318-*$ & $-122.29795-*$ & -144.20704-* & $-193.24606-*$ & $-199.45535-*$ \\
\hline & 24 & & $-43.65476-*$ & $-65.56385-*$ & $-114.60288-*$ & $-120.81217-*$ \\
\hline & 36 & & & -21.90909 & $-70.94811-*$ & $-77.15741-*$ \\
\hline & 48 & & & & $-49.03902-*$ & $-55.24832-*$ \\
\hline & 60 & & & & & -6.20929 \\
\hline
\end{tabular}

*Statistically significant at $\alpha=0.05$.

Table 5 results show that all the ranking of performance was higher for the older age groups in comparison with the younger age groups on each domain and on the scale as a whole except for the adaptive behaviour domain which showed that children of age 60 months have a statistically significant mean higher than that of children of 
age 71.Also there is no statistically significant difference between the two groups (60 months and 71 months) on the total scale score. The results indicate that the scale has a high dicriminitative power according to age.

Second question: What are the reliability indices of the Developmental Assessment of Young Children Second Edition (DAYC-2) Scale (Arabic version) in the Jordan context?

To answer this question, the following reliability measures were calculated:

\subsection{Reliability}

The reliability indices were verified by calculating internal consistency, split half and test-retest methods. The results are as follows:

- Internal consistency: to determine internal consistency of the scale and the subdomains, Kuder Richardson 20 formula was used for each domain and the total items of the scale. Table 5 illustrates the results.

- $\quad$ Split half test: The scale was split into two parts and each child scores on both halves were compared and the reliability coefficients were calculated then corrected by Spearman Brown formula.

- Test-retest: The scale was administrated twice on 20 children with an interval of 14 days. Table 5 shows the correlations between two administrations

Table 6. Reliability coefficients of the DAYC-2 domains score and the total test scores. measured by Kuder-Richardson 20, test-retest, split half using Spearman Brown Correlation equation

\begin{tabular}{lccc}
\hline The Domain & $\begin{array}{c}\text { Test-Retest } \\
(\mathrm{n}=20)\end{array}$ & $\begin{array}{c}\text { Internal consistency: (Kuder-Richardson 20) } \\
(\mathrm{n}=310)\end{array}$ & Split half (spearman equation) $(\mathrm{n}=310)$ \\
\hline Cognitive & 0.998 & 0.984 & 0.749 \\
\hline Social-Emotional & 0.998 & 0.980 & 0.764 \\
\hline Adaptive Behavior & 0.998 & 0.983 & 0.765 \\
\hline Communication & 0.997 & 0.985 & 0.985 \\
\hline Physical & 0.937 & 0.986 & 0.892 \\
\hline Total & 0.996 & 0.996 & 0.991 \\
\hline
\end{tabular}

As we can see from reviewing table.6, the measures of internal consistency show that the value of K-R.20 for the whole scale was 0.996 indicating that the scale has internal consistency. The internal consistency of the domains ranged from (0.980-0.986) which represents good and high consistency coefficients indicating that every domain has valid internal consistency measures. Test-retest results showed that reliability coefficient of the whole scale was (0.996) and the reliability coefficients for the five domains ranged from (0.937 to 0.998$)$.

-The split half reliability coefficient of the whole scale was (.991), and split half reliability coefficients of the five domains ranged from (.749 to.985).These coefficients are considered good and high values.

-The test-retest coefficients for the whole scale was $(0.996)$ and coefficients of the five domains ranged from ( 0.937 to 0.998$)$. The reliability coefficients for test- retest method show that the scale has trustable reliability measures. All the results of the reliability tests methods used show that the the Developmental Assessment of Young Children Second Edition (DAYC-2) scale (Arabic version) has good reliability measures

Third question: What is the items efficacy of the Developmental Assessment of Young Children Second Edition (DAYC-2) Scale (Arabic version)?

\subsection{Point-Biserial Correlation}

To answer this question, the point-biserial correlation coefficients, in which each item is correlated with the total test scores, was used to determine the item's discriminating power. The discriminative coefficients for each domain were as follows:

The cognitive domain: values of point-biserial correlation coefficients of items of cognitive domain ranged from (0.093 to 0.853$)$ and these items had statistical significant values for discrimination between normal and developmentally delayed children except for items $(1,2,3,4,5,75,82,83,85,86,87,88)$. Table 7 shows these results.

The items (1-5) are items which represent skills that are achieved by normally and delayed infants. Therefore, the scores were the same for most of the children in the sample such as(moves hand to mouth, looks at objects for at least 3 seconds)

On the other hand, items $(75,82,83,85-88)$ involved skills that weren't achieved by most of older children (aged 
60monthes or older) such as(counts by rote to 100 ,calculates five or more single digit addition problems, measures length to inch and half inch using ruler). Therefore most the children (normal, delayed) scored (0) on these items.

Table 7. Items discriminative coefficients of the Cognitive domain

\begin{tabular}{|c|c|c|c|}
\hline Item\# & Correlation with the domain & Item\# & Correlation with the domain \\
\hline 1 & a & 45 & $.852 * *$ \\
\hline 2 & $.154 * *$ & 46 & $.848 * *$ \\
\hline 3 & .093 & 47 & $.853 * *$ \\
\hline 4 & $.156^{* *}$ & 48 & $.849 * *$ \\
\hline 5 & $.217 * *$ & 49 & $.849 * *$ \\
\hline 6 & $.345 * *$ & 50 & $.841 * *$ \\
\hline 7 & $.391 * *$ & 51 & $.833 * *$ \\
\hline 8 & $.448 * *$ & 52 & $.835 * *$ \\
\hline 9 & $.451 * *$ & 53 & $.828 * *$ \\
\hline 10 & $.489 * *$ & 54 & $.813 * *$ \\
\hline 11 & $.496^{* *}$ & 55 & $.808 * *$ \\
\hline 12 & $.536 * *$ & 56 & $.819 * *$ \\
\hline 13 & $.552 * *$ & 57 & $.801 * *$ \\
\hline 14 & $.561 * *$ & 58 & $.767 * *$ \\
\hline 15 & $.602 * *$ & 59 & $.784 * *$ \\
\hline 16 & $.632 * *$ & 60 & $.795 * *$ \\
\hline 17 & $.634 * *$ & 61 & $.778 * *$ \\
\hline 18 & $.648 * *$ & 62 & $.752 * *$ \\
\hline 19 & $.682 * *$ & 63 & $.714 * *$ \\
\hline 20 & $.689 * *$ & 64 & $.702 * *$ \\
\hline 21 & $.697 * *$ & 65 & $.693 * *$ \\
\hline 22 & $.700 * *$ & 66 & $.646 * *$ \\
\hline 23 & $.711 * *$ & 67 & $.612 * *$ \\
\hline 24 & $.730 * *$ & 68 & $.619 * *$ \\
\hline 25 & $.730 * *$ & 69 & $.588 * *$ \\
\hline 26 & $.754 * *$ & 70 & $.561 * *$ \\
\hline 27 & $.749 * *$ & 71 & $.563 * *$ \\
\hline 28 & $.772 * *$ & 72 & $.445 * *$ \\
\hline 29 & $.791 * *$ & 73 & $.547 * *$ \\
\hline 30 & $.792 * *$ & 74 & $.512 * *$ \\
\hline 31 & $.805 * *$ & 75 & $.176^{* *}$ \\
\hline 32 & $.808 * *$ & 76 & $.436 * *$ \\
\hline 33 & $.821 * *$ & 77 & $.386^{* *}$ \\
\hline 34 & $.824 * *$ & 78 & $.300 * *$ \\
\hline 35 & $.834 * *$ & 79 & $.327 * *$ \\
\hline 36 & $.833 * *$ & 80 & $.364 * *$ \\
\hline 37 & $.842 * *$ & 81 & $.327 * *$ \\
\hline 38 & $.847 * *$ & 82 & $.121 *$ \\
\hline 39 & $.846 * *$ & 83 & $.280 * *$ \\
\hline 40 & $.849 * *$ & 84 & $.223 * *$ \\
\hline 41 & $.848 * *$ & 85 & $.187 * *$ \\
\hline 42 & $.848 * *$ & 86 & $.187 * *$ \\
\hline 43 & $.851 * *$ & 87 & $.135^{*}$ \\
\hline 44 & $.850 * *$ & 88 & $.135^{*}$ \\
\hline
\end{tabular}

a cannot be computed because at least one of the variables is constant.

*statistically significance at $\alpha=0.05$.

** statistically significance at $\alpha=0.01$. 
The Adaptive behavior domain: values of point-biserial correlation coefficients of items of cognitive domain ranged from ( 0.097 to 0.872$)$ and they had statistical significant values for discrimination between normally and developmentally delayed children except for items $(1,2,3,4,5,57,59,60,61,62,63,64)$. All values are shown in Table8.

The items (1-5) are items which represent skills that are achieved by normally and delayed infants. Therefore, the scores were the same for most of the children in the sample such as (maintains body temperature without external assistance, opens mouth in anticipation of feeding).

On the other hand, items $(57,59,60-64)$ involved skills that were hard to achieve by older children aged (60 months and older) or they didn't have the chance to develop these skills such as (takes shower independently, makes simple breakfast or lunch, takes care of minor cuts by cleaning and applying bandages). Therefore most of the children (normal, delayed) scored $(0)$ on these items.

Table 8. Items discriminative coefficients of the adaptive behavior domain

\begin{tabular}{|c|c|c|c|}
\hline Item\# & Correlation with domain & Item\# & Correlation with domain \\
\hline 1 & .a & 33 & $.856^{* *}$ \\
\hline 2 & .097 & 34 & $.860 * *$ \\
\hline 3 &. $\mathrm{a}$ & 35 & $.871 * *$ \\
\hline 4 & $.187 * *$ & 36 & $.872 * *$ \\
\hline 5 & $.135^{*}$ & 37 & $.872 * *$ \\
\hline 6 & $.380^{* *}$ & 38 & $.844 * *$ \\
\hline 7 & $.384 * *$ & 39 & $.860 * *$ \\
\hline 8 & $.419 * *$ & 40 & $.858 * *$ \\
\hline 9 & $.527 * *$ & 41 & $.832 * *$ \\
\hline 10 & $.565 * *$ & 42 & $.835 * *$ \\
\hline 11 & $.553 * *$ & 43 & $.808 * *$ \\
\hline 12 & $.592 * *$ & 44 & $.786^{* *}$ \\
\hline 13 & $.659 * *$ & 45 & $.825^{* *}$ \\
\hline 14 & $.689 * *$ & 46 & $.815^{* *}$ \\
\hline 15 & $.700 * *$ & 47 & $.782 * *$ \\
\hline 16 & $.703 * *$ & 48 & $.729 * *$ \\
\hline 17 & $.724 * *$ & 49 & $.671 * *$ \\
\hline 18 & $.711 * *$ & 50 & $.676^{* *}$ \\
\hline 19 & $.710^{* *}$ & 51 & $.636^{* *}$ \\
\hline 20 & $.738 * *$ & 52 & $.634 * *$ \\
\hline 21 & $.774 * *$ & 53 & $.559 * *$ \\
\hline 22 & $.780 * *$ & 54 & $.545^{* *}$ \\
\hline 23 & $.794 * *$ & 55 & $.415^{* *}$ \\
\hline 24 & $.798^{* *}$ & 56 & $.463 * *$ \\
\hline 25 & $.806^{* *}$ & 57 & $.230^{* *}$ \\
\hline 26 & $.821 * *$ & 58 & $.348 * *$ \\
\hline 27 & $.829 * *$ & 59 & $.285^{* *}$ \\
\hline 28 & $.830 * *$ & 60 & $.207 * *$ \\
\hline 29 & $.843 * *$ & 61 & $.207 * *$ \\
\hline 30 & $.851^{* *}$ & 62 & $.207 * *$ \\
\hline 31 & $.860 * *$ & 63 & $.207^{* *}$ \\
\hline 32 & $.861^{* *}$ & 64 & $.162 * *$ \\
\hline
\end{tabular}

.a cannot be computed because at least one of the variables is constant.

** Statistically significance at $\alpha=0.01$

The Social emotional domain: values of point- biserial correlation coefficients of items of social emotional domain ranged from (0.093-0.876) and they were statistically significant to discriminate between normally and developmentally delayed children except for items $(1,2,3,4,5)$. The results are illustrated in Table 9. 
The items (1-5) are items which represent skills that are achieved by normally and delayed infants. Therefore, the scores were the same for most of the children in the sample such as (smiles reflexively, stops crying when talked to, picked up, or comforted)

Table 9. Items discriminative coefficients of the social emotional domain

\begin{tabular}{|c|c|c|c|}
\hline Item\# & Correlation with the domain & Item\# & Correlation with the domain \\
\hline 1 & a & 36 & $.869 * *$ \\
\hline 2 & .a & 37 & $.874 * *$ \\
\hline 3 & .093 & 38 & $.871 * *$ \\
\hline 4 & $.178 * *$ & 39 & $.874 * *$ \\
\hline 5 & $.155 * *$ & 40 & $.875 * *$ \\
\hline 6 & $.324 * *$ & 41 & $.869 * *$ \\
\hline 7 & $.375 * *$ & 42 & $.876^{* *}$ \\
\hline 8 & $.439 * *$ & 43 & $.872 * *$ \\
\hline 9 & $.505 * *$ & 44 & $.866^{* *}$ \\
\hline 10 & $.540 * *$ & 45 & $.854 * *$ \\
\hline 11 & $.535 * *$ & 46 & $.850 * *$ \\
\hline 12 & $.554 * *$ & 47 & $.837 * *$ \\
\hline 13 & $.611 * *$ & 48 & $.849 * *$ \\
\hline 14 & $.582 * *$ & 49 & $.841 * *$ \\
\hline 15 & $.608 * *$ & 50 & $.836^{* *}$ \\
\hline 16 & $.628 * *$ & 51 & $.828 * *$ \\
\hline 17 & $.648 * *$ & 52 & $.809 * *$ \\
\hline 18 & $.674 * *$ & 53 & $.816^{* *}$ \\
\hline 19 & $.734 * *$ & 54 & $.814 * *$ \\
\hline 20 & $.756^{* *}$ & 55 & $.801 * *$ \\
\hline 21 & $.766^{* *}$ & 56 & $.794 * *$ \\
\hline 22 & $.765^{* *}$ & 57 & $.762 * *$ \\
\hline 23 & $.773 * *$ & 58 & $.731 * *$ \\
\hline 24 & $.777 * *$ & 59 & $.624 * *$ \\
\hline 25 & $.816^{* *}$ & 60 & $.591 * *$ \\
\hline 26 & $.810 * *$ & 61 & $.559 * *$ \\
\hline 27 & $.834 * *$ & 62 & $.545^{* *}$ \\
\hline 28 & $.851 * *$ & 63 & $.391 * *$ \\
\hline 29 & $.848 * *$ & & $.352 * *$ \\
\hline 30 & $.857 * *$ & & $.354 * *$ \\
\hline 31 & $.869 * *$ & & $.323 * *$ \\
\hline 32 & $.866^{* *}$ & & \\
\hline
\end{tabular}

.a cannot be computed because at least one of the variables is constant.

$* *$ statistically significance at $\alpha=0.01$.

The Physical domain: values of point-biserial correlation coefficients of items of physical domain ranged from (0.078-0.862) and they had statistical significant values for discrimination between normally and developmentally delayed children except for items $(1,2,3,52,54,55,56,57,58,85,86,87)$. All values are shown in Table10

The items (1-3) are items which represent skills that are achieved by normally and delayed infants. Therefore, the scores were the same for most of the children in the sample such as (normal heart rate, when lying on back, can turn head to each side)

On the other hand, items $(52-58,85-87)$ involved skills that were hard to achieve by older children (aged 60 months and older) they didn't have the chance to develop these skills such as (drops a ball and kicks it forward before it hits the floor, catches a small ball (about 4 inch) in hands only, cuts intricate shapes within $1 / 4$ in. of the line). Therefore, most of the children (normal and delayed) scored (0) on these items. 
Table 10. Items discriminative coefficients of the physical domain

\begin{tabular}{|c|c|c|c|}
\hline Item\# & Correlation with the domain & Item\# & Correlation with the domain \\
\hline 1 & .111 & 45 & $.618 * *$ \\
\hline 2 & $.168 * *$ & 46 & $.588 * *$ \\
\hline 3 & $.169 * *$ & 47 & $.561 * *$ \\
\hline 4 & $.340 * *$ & 48 & $.554 * *$ \\
\hline 5 & $.302 * *$ & 49 & $.476 * *$ \\
\hline 6 & $.380 * *$ & 50 & $.426 * *$ \\
\hline 7 & $.447 * *$ & 51 & $.321 * *$ \\
\hline 8 & $.623 * *$ & 52 & $.172 * *$ \\
\hline 9 & $.654 * *$ & 53 & .088 \\
\hline 10 & $.687 * *$ & 54 & .088 \\
\hline 11 & $.680 * *$ & 55 & .078 \\
\hline 12 & $.733 * *$ & 56 & $.164 * *$ \\
\hline 13 & $.751 * *$ & 57 & $.257 * *$ \\
\hline 14 & $.771 * *$ & 58 & $.236 * *$ \\
\hline 15 & $.772 * *$ & 59 & $.606 * *$ \\
\hline 16 & $.799 * *$ & 60 & $.619 * *$ \\
\hline 17 & $.802 * *$ & 61 & $.653 * *$ \\
\hline 18 & $.807 * *$ & 62 & $.724 * *$ \\
\hline 19 & $.818 * *$ & 63 & $.725 * *$ \\
\hline 20 & $.835 * *$ & 64 & $.773 * *$ \\
\hline 21 & $.850 * *$ & 65 & $.823 * *$ \\
\hline 22 & $.854 * *$ & 66 & $.845 * *$ \\
\hline 23 & $.855^{* *}$ & 67 & $.829 * *$ \\
\hline 24 & $.857 * *$ & 68 & $.845 * *$ \\
\hline 25 & $.858 * *$ & 69 & $.838^{* *}$ \\
\hline 26 & $.860 * *$ & 70 & $.808 * *$ \\
\hline 27 & $.861 * *$ & 71 & $.800 * *$ \\
\hline 28 & $.861 * *$ & 72 & $.760 * *$ \\
\hline 29 & $.861 * *$ & 73 & $.757 * *$ \\
\hline 30 & $.860 * *$ & 74 & $.745 * *$ \\
\hline 31 & $.854 * *$ & 75 & $.725 * *$ \\
\hline 32 & $.859 * *$ & 76 & $.698 * *$ \\
\hline 33 & $.862 * *$ & 77 & $.655 * *$ \\
\hline 34 & $.857 * *$ & 78 & $.623 * *$ \\
\hline 35 & $.859 * *$ & 79 & $.615^{* *}$ \\
\hline 36 & $.851 * *$ & 80 & $.524 * *$ \\
\hline 37 & $.847 * *$ & 81 & $.577 * *$ \\
\hline 38 & $.824 * *$ & 82 & $.526^{* *}$ \\
\hline 39 & $.817 * *$ & 83 & $.496 * *$ \\
\hline 40 & $.808 * *$ & 84 & $.382 * *$ \\
\hline 41 & $.780 * *$ & 85 & $.258 * *$ \\
\hline 42 & $.746^{* *}$ & 86 & $.198 * *$ \\
\hline 43 & $.670 * *$ & 87 & $.145^{*}$ \\
\hline 44 & $.633 * *$ & 88 & \\
\hline
\end{tabular}

** statistically significance at $\alpha=0.01$.

*statistically significance at $\alpha=0.05$.

The Communication domain: values of point- biserial correlation coefficients of items of communication domain ranged from (0.064-0.892) and these items were statistically significant to discriminate between normally and developmentally delayed children except for items $(1,2,3,4,5,36,37,38,39,40,41,42,67,76$, 77, 78). The results are illustrated in Table 11. 
The items (1-5) are items which represent skills that are achieved by normally and delayed infants. Therefore, the scores were the same for most of the children in the sample such as (normal breathing rate, quieted by music).

On the other hand, items $(37-40,41,42,67,76-78)$ involved skills that were hard to achieve by older children aged (60 months and older) or they didn't have the chance to develop these skills such as (can identify at least three complete sentences, states differences between objects for at least three objects, uses irregular comparatives correctly). Therefore most the children scored (0) on these items.

Table 11. Discriminative coefficients of the communication domain

\begin{tabular}{|c|c|c|c|}
\hline Item\# & Correlation with the domain & Item\# & Correlation with the domain \\
\hline 1 &. $\mathrm{a}$ & 40 &. $\mathrm{a}$ \\
\hline 2 &. $\mathrm{a}$ & 41 & $.231 * *$ \\
\hline 3 &. $\mathrm{a}$ & 42 & $.252 * *$ \\
\hline 4 & $.189 * *$ & 43 & $.379 * *$ \\
\hline 5 & $.292 * *$ & 44 & $.489 * *$ \\
\hline 6 & $.375 * *$ & 45 & $.596 * *$ \\
\hline 7 & $.482 * *$ & 46 & $.668 * *$ \\
\hline 8 & $.639 * *$ & 47 & $.722 * *$ \\
\hline 9 & $.654 * *$ & 48 & $.738 * *$ \\
\hline 10 & $.685 * *$ & 49 & $.797 * *$ \\
\hline 11 & $.722 * *$ & 50 & $.801 * *$ \\
\hline 12 & $.772 * *$ & 51 & $.823 * *$ \\
\hline 13 & $.795 * *$ & 52 & $.854 * *$ \\
\hline 14 & $.833 * *$ & 53 & $.867 * *$ \\
\hline 15 & $.828 * *$ & 54 & $.890 * *$ \\
\hline 16 & $.846^{* *}$ & 55 & $.893 * *$ \\
\hline 17 & $.849 * *$ & 56 & $.892 * *$ \\
\hline 18 & $.879 * *$ & 57 & $.891 * *$ \\
\hline 19 & $.881 * *$ & 58 & $.896 * *$ \\
\hline 20 & $.867 * *$ & 59 & $.888 * *$ \\
\hline 21 & $.886^{* *}$ & 60 & $.881 * *$ \\
\hline 22 & $.887 * *$ & 61 & $.889 * *$ \\
\hline 23 & $.867 * *$ & 62 & $.880 * *$ \\
\hline 24 & $.892 * *$ & 63 & $.848 * *$ \\
\hline 25 & $.887 * *$ & 64 & $.811 * *$ \\
\hline 26 & $.867 * *$ & 65 & $.842 * *$ \\
\hline 27 & $.823 * *$ & 66 & $.803 * *$ \\
\hline 28 & $.812 * *$ & 67 & .104 \\
\hline 29 & $.732 * *$ & 68 & $.762 * *$ \\
\hline 30 & $.727 * *$ & 69 & $.764 * *$ \\
\hline 31 & $.604 * *$ & 70 & $.711 * *$ \\
\hline 32 & $.617 * *$ & 71 & $.718 * *$ \\
\hline 33 & $.526 * *$ & 72 & $.558 * *$ \\
\hline 34 & $.494 * *$ & 73 & $.365^{* *}$ \\
\hline 35 & $.305 * *$ & 74 & $.529 * *$ \\
\hline 36 & $.291 * *$ & 75 & $.443 * *$ \\
\hline 37 & $.143 *$ & 76 & $.265 * *$ \\
\hline 38 & -.064 & 77 & $.296 * *$ \\
\hline 39 & .a & 78 & $.139 *$ \\
\hline
\end{tabular}

.a cannot be computed because at least one of the variables is constant.

*statistically significance at $\alpha=0.05$.

$* *$ Statistically significance at $\alpha=0.01$ 


\section{Discussion and Conclusion}

This Observational analytical study aimed to assess the efficacy of the Developmental Assessment of Young Children Scale (Arabic version) in detecting developmental delay in young children aged (0-71) months. This aim was attained by establishing the scale psychometric characteristics in terms of validity, reliability and item efficacy. Overall, the results showed that the scale has good psychometric indices.

The questions stated in the purpose of our study were positively supported by the results of the study.

Firstly, the translated version of the Developmental Assessment of Young Children, second edition (DAYC-2) into Arabic showed content validity indicating the possibility of its use in studies similar to ours.

The psychometric characteristics of the scale were established. The results showed that the DAYC-2 (Arabic version) has satisfied three types of reliability measures (Internal consistency, test-retest, split half). The scale met content and discriminant validity. Independent 2-sample t-test showed that the scale differentiated significantly between normal and delayed children. One-way ANOVA showed that the scale differentiates between the performances of children according to age level. Hence the scale is suitable to be used to rank the performance of children aged from birth to 71 months.

Item discriminant refers to the degree to which an item differentiates correctly among test takers in the behaviour that the test is designed to measure (Anastasi \& Urbina, 1997, p. 179).

Nunnally and Bernstein (1994) noted that items with discriminating power of 0.20 or more will likely be satisfactory if the test is fairly long but in a short test, larger item values are required. Item efficacy (Item discriminant) of the DAYC-2 (Arabic version) was tested by computing point-biserial correlation coefficients among the items. The resulting values of point-biserial correlations of the scale compared well with Nunnally and Bernstein (1994) most rigorous criterion, and hence the current study values have met fairly with their stated criteria.

In DAYC-2 Test review, Swartzmiller (2014) pointed out "a minimum correlation of.90 was considered satisfactory, as reliability of .90 has been recommended for tests used to make important decisions" (Salvia, Ysseldyke, \& Bolt, 2010; Sattler, 2008; Swartzmiller, 2014, p. 578).

In Swartzmiller (2014) review, DAYC-2's Correlation coefficients for the total score ranged from .98 to 0.99. In our current study, DAYC-2 (Arabic version) internal consistency had reached similar results (0.996). This gives support to the scale to be implemented in research of developmental delay detection and early intervention referral decisions.

Based on the fact that the developmental assessment of young children second edition (Arabic version) has good psychometric properties, it is recommended to be used in Jordan context and in other Arab countries.

We acknowledge several limitations in this study. Sample size, place of administration of the scale are some of these limitations whereby The DAYC-2 Scale(Arabic version) was administrated only on 310 children in the neurodevelopmental pediatric clinic in Jordan university hospital, two special education centers in Capital Amman, the Institute for family health - Noor al Hussein foundation and 2 preschools in Capital Amman. The psychometric properties of the developmental assessment scale used and research methodology employed might have also posed results' limitation.

The authors plan to use the scale in identifying normally and delayed developmentally children in a future study to compute its false positive and false negative indices. They also acknowledge that the Arabic version of the scale needs more investigation. Implementing this study on larger sample to standardize the scale and extract norms for Jordanian children would be beneficial.

\section{References}

Abu Hammour, B., Mattar, J., \& Al-Hmooz, H. (2015). A Pilot Study for Standardizing an Arabic Version of Woodcock-Johnson Cognitive and Achievement Tests (WJ) in Jordan. Educational Studies Journal, 42(2), 499-515.

Aiken, L. R., \& Groth-Marnat, G. (2006). Psychological testing and assessment (12 ${ }^{\text {th }}$ ed.). Botson MA: Pearson Education.

American Academy of Pediatrics. (2001). Developmental Surveillance and Screening of Infants and Young Children with Disabilities (Committee on Children With Disabilities). Pediatrics, 108, 192-196.

Anderson, L. (2006). Use of the Communication Development Subtest of the DAYC as a Teacher-Administered Language Screening Instrument. Communication Disorders Quarterly, 27(4), 206-212. 
Bagnato, S. J. (2007). Authentic assessment for early childhood intervention: Best practices. London: Guilford Press.

Boehm, A., \& Brassard, R. (2005). Preschool Assessment: Principles and Practices. Guilford Press.

Boyle, C. A., Decoufle, P., \& Yeargin-Allsopp M. (1994). Prevalence and health impact of developmental disabilities in US children. Pediatrics, 93, 399-403

Buros Mental Measurement Institute. (2007). Review of the Developmental Assessment of Young Children (DAYC). Buros mental measurement Yearbook (14th ed.).

Chung, C., Liu, W., Chang, C., Chen, C., Tang, S., \& Wong, A. (2011). The Relationship Between Parental Concern and Final Diagnosis in Children With Developmental Delay. Journal of Child Neurology, 26(4),413-419.

Earls, M., Andrew, J., \& Hay, S. (2009). A Longitudinal Study of Developmental and Behavioral Screening and Referral in North Carolin's Assuring Better Child health and Development Participating Practices. Clinical Pediatrics, 48(8), 824-834.

Guralnick, M. J. (2008). International Perspectives on Early Intervention: A Search for Common Ground. Journal of Early Intervention, 30(2), 90-101. http://dx.doi.org/10.1177/1053815107313483

Guralnick, M. J., \& Bricker, D. (1987). The effectiveness of early intervention for children with cognitive and general developmental delays. In M. J. Guralnick, \& F. C. Bennett (Eds.), The Effectiveness of Early Intervention for At-risk and Handicapped Children (pp. 115-173). San Diego: Academic Press.

Individuals with Disability Education Act Amendments of 1997 [IDEA]. (1997). Retrieved from http://thomas.loc.gov/home/thomas.php

Jammous, Z. (1983). Developing Cain-Levine Social Competency Scale (Unpublished doctoral dissertation). Jordan University, Amman, Jordan.

Khatib, B., \& Batsh, M. (2008). Constructing A Model For Detecting Developmental Delay in Cognitive, Social-Emotional, and language Domain Among Jordanian Children Aged 3-8 years (Doctoral Dissertation).

Khatib, J. (2015). Early Intervention: Special Education in Early Childhood. Amman, Dar al Faker.

Killany, A. (1981). Stanford-Binet Intelligence scale Manual. Alasdeqaa Press, Amman, Jordan.

Labdy, N. (1995). Developing Jordanian version of Primary Levels of Cognitive Skills Test for Children aged (8-11) years (Unpublished master's thesis). Jordan University, Amman, Jordan.

Levy, Y., Ornoy, A., \& Nevo, Y. (2011). Special Issue on Developmental Delay. Developmental Disabilities Res. Rev., 17, 57-58. http://dx.doi.org /10.1002/ddrr.1100

Marks, K. P., Glascoe, F. P., \& Macias, M. M. (2011). Enhancing the algorithm for developmental-behavioral surveillance and screening in children 0 to 5 years. Clinical Pediatrics, 50(9), 853-868. http://dx.doi.org/0009922811406263

Marks, P., \& LaRosa, C. (2012). Understanding Developmental-Behavioral Screening Measures. Pediatrics, 33(10), 448-458. http://dx.doi.org/10.1542/pir.33-10-448

Meisels, J., \& Atkins-Burnett, S. (1999). Assessing Intellectual and affective development before age three: A perspective on changing Practices. Food and Nutrition Bulletin, 20(1). The United Nations University.

Milne, S. L., McDonald, J. L., \& Comino, J. E. (2012). Adaptive function in preschoolers in relation to developmental delay and diagnosis of autism spectrum disorders: Insights from a clinical sample. Autism, 17(6), 743. http://dx.doi.org/1010.1177/1362361312453091

Neisworth, J. T., \& Bagnato, S. J. (2004). The mismeasure of young children: The authentic assessment $\begin{array}{lllll}\text { alternative. Infants } \quad \& \quad \text { Young } & \text { Children, } & 17(3), & \text { 198-212. }\end{array}$ http://dx.doi.org/10.1097/00001163-200407000-00002

Nunnally, J. S., \& Bernstein, I. H. (1994). Psychometric theory (3rd ed.). New York, NY: McGraw-Hill.

Ogletree, B. T. (2001). Review of the Developmental Assessment of Young Children. In B. S. Plake, \& Impara (Eds.), The fourteenth mental measurement yearbook (pp. 390-391). Lincolin, Buros Institute of Mental Measurements. University of Nebraska Press

Salvia, J., Ysseldyke, J., \& Bolt, S. (2010). Assessment in special and Inclusive Education (11th ed.). New York, 
NY: Houghton-Mifflin.

Sattler, J. M. (2008). Assessment of children: Cognitive foundations (5th ed.). La Mesa, CA: Jerome M. Sattler Publisher.

Shonkoff, J. P., \& Phillips, D. A. (Eds.). (2000). From neurons to neighborhoods: The science of early childhood development. Washington, D.C.: National Academies Press. http://dx.doi.org/10.17226/9824

Sices, L. (2007). Developmental screening in primary care: The effectiveness of current practice and recommendations for improvement. Commonwealth Fund.

Sices, L., Feudtner, C., McLaughlin, J., Drotar, D., \& Williams, M. (2004). How Do Primary Physicians Manage Children With Possible Developmental Delays? A National Survey With an Experimental Design. Pediatrics, 113(2), 274-282.

Snow, C. E., \& Van Hemel, S. B. (Eds.). (2008). Early childhood assessment: Why, what, and how. Washington, D.C.: National Academies Press.

Swartzmiller, M. (2014). Test Review: Developmental Assessment of Young Children-Second Edition $\begin{array}{llll}\text { (DAYC-2). Journal of psychological } & \text { Assessment, }\end{array}$ http://dx.doi.org/10.1177/0734282913518380

The Higher Council for Affairs of Persons with Disabilities. (2007). National Strategy for people with disabilities (2007-2015). Amman, Jordan.

Thomas, S., Cotton, W., Pan, W., \& Ratliff-Schaub, K. (2012). Comparison of Systematic Developmental Surveillance with Standardized Developmental Screening in Primary Care. Clinical Pediatrics, 51(2), 154. http://dx.doi.org/10.1177/0009922811420711

Tripp, H. E. (2015). Predicting Future Special Education Eligibility from Developmental Assessment of Young Children (DAYC) Scores (Doctoral dissertation). Available from ProQuest Dissertation \& Theses: Full Text (3714288).

Voigt, R. G., Llorente, A. M., Jensen, C. L., Fraley, J. K., Barbaresi, W. J., \& Heird, W. C. (2007). Comparison of the validity of direct pediatric developmental evaluation versus developmental screening by parent report. Clinical pediatrics, 46(6), 523-529. http://dx.doi.org/ 10.1177/0009922806299100

Voress, J. K., \& Maddox, T. (2013). Developmental Assessment of Young Children (2nd ed.). Austin, TX: PRO-ED.

Watson, T. S. (2001). Review of the Developmental Assessment of Young Children. In B. S. Plake, \& Impara (Eds.), The fourteenth mental measurement yearbook (pp.392-394). Lincolin, NE: Buros Institute of Mental Measurements. University of Nebraska Press.

Wortham, S. C. (2012). Assessment in early childhood education. University of Texas. San Antonio, Emerit.

Yao-Chia, C., Hsu, C., Chiu, N., Shuaun, L., Tzang, R., \& Yang, C. (2011). Other Impairment Associated With Developmental Language Delay in Preschool-Aged Children. Journal of Child Neurology, 26(6), 714-717. http://dx.doi.org/10.1177/088307381038933

\section{Copyrights}

Copyright for this article is retained by the author(s), with first publication rights granted to the journal.

This is an open-access article distributed under the terms and conditions of the Creative Commons Attribution license (http://creativecommons.org/licenses/by/4.0/). 